\title{
Struggling with juggling: Gender and work/life balance in the legal professions
}

\author{
${\text { Ivana } \text { Bacik }^{a}{ }^{a}, \text { Eileen Drew }}^{b}$ \\ ${ }^{a}$ Law School, Trinity College Dublin, Ireland \\ ${ }^{\mathrm{b}}$ Department of Statistics \& Centre for Gender and Women's Studies, Trinity College Dublin, Ireland
}

\section{Synopsis}

Since the 1960s, women have begun emerging into the public sphere and the public/private divide has been eroding. However, women's participation in the public sphere remains limited by the ongoing need to do two jobs ('the double day'), working both in the home and in the labour market. Thus, a study conducted into gender difference in the legal professions in Ireland [Bacik, Ivana, Costello, Cathryn, and Drew, Eileen (2003), Gender InJustice: Feminising the legal professions?, Trinity College Dublin Law School, Dublin.] found that, while women are entering legal studies in increasing numbers, they remain concentrated at the lower levels of practice. Women lawyers have immense difficulty in achieving work/life balance, due to the long hours culture, an ingrained hostility to flexible work arrangements, and to the fact that they retain a disproportionate caring burden in the private sphere. Changes in the structuring of legal work are clearly required to address this gender imbalance and the associated work/life imbalance — but cultural changes are ultimately needed to end the ongoing "struggle to juggle."

\section{Introduction}

A major theme of feminist literature is the emergence of women into the public sphere after the second wave of the feminist movement in the 1960s and the erosion of the public/private dichotomy (Eisenstein, 1981; O’Donovan, 1985; Olsen, 1983; Pateman, 1988). Pateman's (1988) concept of the 'sexual contract' challenges the assumption that labour market work and work at home are independent of each other. Rather, she has highlighted the gendered division of labour whereby women's caring role is institutionalised in the home, in a 'contract' which leaves men free to sell their labour on a public market. Furthermore, Thornton (1996, p. 15) cites Pateman's concept in stating that the very:

construction of the feminine in terms of corporeality, reproduction, love, and peculiarity has supposedly rendered women unfit for participation in public life, as these characteristics by their nature prevent women from developing a sense of justice.

The public and private divide, although no longer impermeable, remains. As Eisenstein (1981, p. 22) writes, 'although the meaning of 'public' and 'private' changes in concrete ways, the assignment of public space to men and private space to women is continuous in Western history." Walby (1990) has extended this to the theory of patriarchy and the phenomenon of occupational segregation as a crucial mechanism for ensuring women's subordination. According to Walby, the strategy of exclusion was the prevailing one in 19th century Britain that evolved into a segregation strategy by the 20th century in Britain and elsewhere. Hence, this represented a shift from 'private' patriarchy in which women were excluded from paid work and restricted to the domestic sphere to 'public' patriarchy in which women gained limited access to lower grade and lower paid work, often performed on a part-time basis. 
In particular, the gendered reality of caring continues to affect the participation of women in the public sphere in three distinct ways. First, in practice for many women, it is difficult to do two jobs ('the double day') in the home and in the labour market, particularly if they have dependent children or are caring for an elderly parent. This is not to suggest that all women bear caring responsibilities, or that no men do. However, the dual burden of work and care afflicts women disproportionately.

Second, the construction of women as paid workers has been notably shaped by the assignation of responsibility for caring. Women are generally employed to 'soften' or humanise the environmental backdrop of the workplace, and this may be reflected both in the tasks they are assigned and in the behaviour they are expected to demonstrate. Thus, women in paid work are allocated or choose roles that are derivative of caring, as their area of specialisation or as a gloss on their designated work. According to Mata Greenwood (2001, p. 71) learned gender roles (e.g. as parent, housekeeper, provider) largely determine the type of work men and women do: "For example, given their traditional role as homemakers, more female than male workers tend to combine economic activities with household (non-economic) activities, to work intermittently over the year and to work closer to home." She claims that a further area of gender differentiation occurs in the allocation of resources and benefits among household members, thus determining their different needs and constraints. Hence, female participation in the labour market is highly dependent on their marital status and whether they have small children and/or have to care for other persons in their households.

Hakim (2000, p. 283) has propounded 'preference' theory to explain the "remarkable success and effectiveness of male solidarity and male organisation in all modern societies." She attributes the heterogeneity of women's preferences and interests: "for a lifestyle centred on the home, or on public life, with or without role segregation" as representing fundamental divisions through which male dominance is sustained in modern societies.

Labour market segmentation has also been used to explain women's disadvantage in assigning women disproportionately to the 'secondary' sector and men to the 'primary' sector (Anker, 1998). These parallel sectors would normally offer radically different pay, conditions, and job security. However, in relation to the legal professions, the entry routes and professional requirements do not support labour market segmentation theory per se. However, they do offer insights into explaining vertical occupational segregation according to gender, where men are more likely than women hold better quality jobs in the same occupations (Anker, 1998). In the context of the legal professions, for example, research into the effect of gender upon legal careers tends to show that family law in particular emerges as a particular area of specialisation for women. There is also evidence that the areas in which women are concentrated have lower earnings thresholds than those dominated by men.

Third, an additional problem arises in careers like those in the legal profession where emphasis is placed upon the possession of 'social capital.' This concept, derived from Bourdieu (1986), refers to the number of culturally, economically or politically useful relations accumulated by an individual. A person with low educational capital but high social capital may advance further in some professions than a person with high educational capital but low social capital. In the context of legal careers, Sommerlad and Sanderson (1998, p. 17) write that "A woman can work hard, perform exceptionally in examinations, become expert in her field, only to discover that she is regarded as 'a good technician,' a 'back room girl,' since what may be required for 'partnership material' is someone who is 'clubbable,' or 'ladsy' or attractive." Thornton (1996) similarly considers that the culture of the legal workplace rests on a 'fraternal contract,' meaning that engaging in after-hours socialisation, or excelling in sports talk or sports activities is crucial to progress in legal careers. Jack and Crowley Jack (1989) even argue that the role of sport is so prominent in the promotion of lawyers that learning to excel at a sport is "the first stage of pre-law training."

These and other studies have found that women are often at a disadvantage in the accrual of this type of social capital, both in terms of engaging in sport or other afterhours socialisation. It is true that men who do not conform to a heterosexist model of 'hegemonic masculinity' (Connell, 1995; Collier, 1998) are also at a similar disadvantage in being, like many women, overtly or subtly excluded from such activities. However, women face especial difficulty in accruing social capital because of the disproportionate caring burden that they tend to shoulder in the private sphere.

Particular problems for women are therefore associated with a 'long hours' culture. Sommerlad and Sanderson argue that the emphasis on long hours as the key determinant of 'commitment' to work, and the related elevation of 'commitment' as the overarching professional value, leads to a situation in which women lawyers are significantly disadvantaged, again due to the fact that women continue to be the primary caregivers, even in dual-earner family households.

Restrictions like these on women's entry into, and participation or progress within, the public sphere are therefore clearly evident in legal practice, just as they are in other occupations and professions. In particular, it is 
especially difficult for women to achieve a satisfactory balance between work and home life, if they wish to advance their legal careers.

\section{'Gender InJustice' - the 2003 Irish lawyers' survey}

This paper takes up these themes explored in literature elsewhere in order to examine the different home/family circumstances of women and men in the legal professions in Ireland, to determine the degree to which both female and male lawyers have been able to access and achieve work/life balance, and to assess the extent to which a gender difference exists in the experiences of juggling work and home commitments among lawyers. ${ }^{1}$

In doing so, the paper draws upon an extensive study recently conducted into the position of women and men in the Irish legal professions, published in 2003 as 'Gender InJustice' (Bacik, Costello, \& Drew, 2003). ${ }^{2}$ This study, the first of its kind to be conducted in Ireland, aimed to document and analyse significant recent change in gender breakdown among lawyers, and to highlight the increasing feminisation of the legal profession (women now make up $66 \%$ of law students nationally in Ireland). Despite this change, anecdotal evidence had tended to show that discrimination against women in legal practice was still a real problem, so the study also sought to examine the extent to which gender discrimination occurs. The particular difficulties associated with protecting against gender discrimination, given the high levels of self-employment attached to legal practice in Ireland, were also examined.

Quantitative information was gathered from the professional bodies on the age, gender, and professional status of lawyers in Ireland, while qualitative data were sought on the motivations and aspirations, career paths, family status, and experience of discrimination, of male and female lawyers. In order to gather this data, a mailed questionnaire was issued to 3422 recipients in May 2002

\footnotetext{
${ }^{1}$ The legal profession in Ireland is divided into two branches: solicitors and barristers. Barristers' work is primarily in litigation and courtroom advocacy, while solicitors tend to do a broader range of work including conveyancing (property transactions), wills and probate, commercial transactions, and some litigation. Barristers are self-employed and work independently. Unlike in the UK, they may not form chambers. They depend on solicitors' instructions for their cases. Solicitors, in contrast, deal directly with clients. Many solicitors are employees of firms or self-employed partners in law firms. Sole practice is also a feature of the legal profession for solicitors in Ireland, in particular outside of Dublin. Each branch of the profession is regulated by its own professional body; the Law Society for solicitors and the Bar Council for barristers.

${ }^{2}$ The survey was funded by the Department of Justice, Equality, and Law Reform under the Equality for Women Measures of the Operational Programmes of the National Development Plan 20002006 as the first national study of gender in legal practice in Ireland.
}

for self-completion. In total, 788 legal professionals completed and returned the questionnaire, including 32 judges, 518 solicitors, 220 barristers, and 18 other legal professionals (a response rate of $23 \%$ ). Statistical analysis of the information gathered through the questionnaire was conducted based on Pearson's chi-square test.

Further qualitative data were collected through a series of focus groups and interviews conducted with legal professionals. Three women-only focus groups were held involving legal professionals in which a total of 13 women participated. A further focus group involving male lawyers was also held with five participants. Two further mixedgender focus groups comprising students on the postgraduate training courses run by solicitors' and barristers' professional bodies were also held, involving nine students in total. In addition, interviews were conducted with eight individual women who had each achieved a noteworthy status within the Irish legal profession, to gain further in-depth insights into their own career progression.

The findings of the study established that structural gender discrimination exists in the legal professions in Ireland, and that despite the many advances made by women lawyers in recent years, barriers to women's career progression remain, particularly in the form of exclusionary practices, pay inequity, and structures that impede the achievement of work/life balance. In this paper, however, it is proposed to focus in particular on the findings of the study related to work/life balance issues.

\section{Work/life imbalance—context}

The issues of balance between work and non-work life and the gender division of labour can be traced to the 19th century. Noting the 'long hours' culture in law and the absence of any flexibility in the existing structures, Leila Robinson, who was first admitted to the Massachusetts State Bar in 1882, asked if "it is practicable for a woman to successfully fulfill the duties of wife, mother, and lawyer at the same time?" (Boston Bar Association Task Force, 1999, p. 5). Such structures are not limited to working hours but spill over into the fraternal camaraderie associated with professional socialising (such as playing golf), referred to above and identified as crucial to progress in the legal professions. In such a culture, it is difficult to introduce flexible working arrangements, career breaks, or family friendly workplace practices.

Thus concern about the difficulty of achieving work/life balance in the legal profession, and the specific impact of this difficulty upon women lawyers, continues today. A recent American Bar Association (ABA, 2001) study was devoted exclusively to the topic, noting that the proportion of women who doubt the possibility of combining work 
and family life has tripled over the last two decades, due at least in part to the exponential increase in expected billable hours. A survey conducted by the ABA of 1400 lawyers found that, while $95 \%$ of firms have policies that allow parttime work, only $3 \%$ of lawyers actually work part-time.

The elements of pressure to work longer hours, and a tendency for flexibility to be viewed with disdain, as signalling a lack of interest in career progression, are not confined to the legal professions. Another Irish study (Drew, Murphy, \& Humphreys, 2003) captured information on 912 organisations in manufacturing and private/ public services. This study showed that the higher the level of responsibility, the more likely it was that staff had to work longer than their standard hours. For senior managers/ professionals, the level was $86 \%$ of all 912 organisations surveyed, while for junior managers/professionals it was $61 \%$ of all organisations. In contrast, manual/non-manual workers were expected to work beyond their standard hours in $30 \%$ of the respondent organisations. Furthermore, overtime or time off in lieu was least common among managers compared with manual/non-manual workers who are more likely to be compensated.

The study also showed that organisations need flexibility in order to conduct their day-to-day operations but that this flexibility tended to be unidirectional. While part-time working, flexitime, and home working were available in a majority of organisations, the take-up rate was extremely low and mainly confined to women in clerical posts (Drew et al., 2003). Employers tended not to make flexible working available to staff for reasons associated with customer needs, production process/ shifts, and seniority/grade. Others mentioned small size of business, additional costs, business needs, and lack of demand by employees.

In a parallel survey of 1006 employees in five organisations, it was noted that most employees believe that, while their current working arrangements suit their family/personal life, there is evidence of 'long hours' as a standard arrangement, often without any form of compensation (Drew et al., 2003). This occurs mainly in order to get the job done or when there is an increased workload or a backlog. The survey showed that $62 \%$ of male employees and $38 \%$ of female employees work longer than standard hours. More women avail of flexitime, while working from home is more popular to men. Part-time working is very rare among male employees $(1 \%)$ but is availed of by a substantial proportion of female employees (17\%) (Drew et al., 2003).

Among employees who can access flexible working, the perceived advantages are in easing commuting/parking, greater autonomy, quality time with family and/or savings on childcare, and ability to schedule day time personal appointments. The main disadvantages cited are difficulties in providing cover/scheduling work and adverse impact on promotional prospects, since there is a perception that takeup signals that an employee is not fully committed, and a proportional reduction in earnings (Drew et al., 2003).

The findings of the employer/employee surveys in Ireland have validated international patterns in which workload pressures clearly prevent some employees from taking up flexible work arrangements; they simply feel that pressures of work would not allow it. These barriers appear to be particularly strong among employees working long hours, in professional environments or where an organisation is already experiencing staff shortages.

Concerns that availing of family friendly working arrangements would damage career prospects are evident in the international literature. Research conducted by Kodz, Harper, and Dench (2002) and Hogarth et al. (2001), for example, provides strong support for the belief that availing of family friendly working arrangements would be seen as a lack of commitment to one's career. Men, in particular, tended to claim that availing of family friendly working arrangements would not be regarded as 'acceptable.'

The absence at senior management level of role models who had either worked, or are currently working, in flexible arrangements further heightened these concerns. Kodz et al. (2002) had surveyed UK participants who had taken-up family friendly working arrangements, a portion of whom referred to work loads that were not reduced commensurate to their reduction in hours, and as a result who ended up bringing home work to complete, for which they were not paid.

Thus, despite increasing rhetoric from policymakers and legislators about the need to ensure work/life balance generally, a culture of long hours and of hostility to flexible working appears to prevail in a wide range of professions and occupations. The remainder of this paper explores the extent to which the same culture exists among Irish lawyers. Responses received to the 2003 survey indeed demonstrate that many of the difficulties with achieving work/life balance identified in the national and international literature, are also evident for legal professionals in Ireland (Bacik et al., 2003).

\section{Gender and age profile of Irish lawyers}

The 2003 lawyers' survey found that the legal professions in Ireland are becoming increasingly feminised, due to the high entry levels of female graduates since the 1980s. This is borne out by the finding that 66 per cent of undergraduate law students were women in 2001/ 2002. Women have been entering legal studies in Ireland in large numbers since the 1980s. In fact, equal gender 
balance in the study body at university law courses occurred in the mid-1980s (Bacik et al., 2003, p. 88).

In $2002,41 \%$ of solicitors and $34 \%$ of barristers in Ireland were women, but these women are concentrated at the lower ends of both professions. At the more senior level, legal practice remains resolutely male-dominated. Only one in five judges were women in 2002 (21\%) and among barristers women comprised only $9 \%$ of Senior Counsel. In the 12 largest solicitors' firms in Ireland, women made up, on average, only $24 \%$ of partners. Women constituted more than one-third of the partners $(36 \%)$ in only one of those firms.

Female respondents to the Irish survey had a younger age profile than their male counterparts. More than twothirds $(67 \%)$ were aged under 40 years of age, compared with $40 \%$ of the men. These differences were statistically highly significant, confirming the increasing feminisation of the legal professions. The smaller proportion of women among older legal professionals may be presumed to reflect the historic fact of lower levels of entry to the professions, and/or higher levels of wastage/ exit from legal careers, by women.

\section{Family status-gender differences}

Allied to their younger age profile, female respondents were also less likely than their male colleagues to be married or formerly married. Over one-third of the women (34\%) were single while this applied to only one-fifth (22\%) of the men; two-thirds of whom $(68 \%)$ were married. In contrast, only half of the women who responded $(51 \%)$ were married. However, $11 \%$ of the women were living with their partner, compared with $5 \%$ of the men. These differences between women and men are highly significant.

A total of 346 respondents had children. The proportion of women with children was lower among survey respondents, $43 \%$ compared with two-thirds of men $(67 \%)$. This difference was highly significant. While the women comprise $65 \%$ of survey respondents, they collectively had less than half of the children (49\%). Few of the fathers had only one child -28 in total compared with 57 women. Men were more likely to have more than three children, whereas female respondents had smaller families. In noting the rise in childlessness in many countries, Hakim (2000) refers to this trend as 'voluntary,' arising from the contraceptive revolution, and an expression of women's choice. However, the survey responses among women in the Irish legal professions point to at least some degree of involuntary childlessness or 'postponed parenting,' where women tended to delay having children due to their fears about the consequences of parenthood for their career progress. One focus group participant, herself both a mother and a partner in a solicitors' firm, said that she had "waited until I was well in as a partner. Instinctively I felt it would be to my disadvantage earlier." Another participant, a younger newly qualified solicitor, said about her aspirations to be a mother that she "would feel I was selling myself out, studying so long...I would like to be established as a solicitor before that..."

The perception among women lawyers that they need to delay having children if they wish to succeed in their careers may be seen as justified at least partially on an examination of the childcare arrangements of those men and women lawyers who are parents. The gender differences were statistically very significant. Fewer than 1 in 10 of the women with children $(9 \%)$ could rely on childminding by their partner at home, compared with two-thirds of the men (65\%). Hence, women were much more likely to use a childminder (79\%), compared with $21 \%$ of men. Men were less likely than women to use a créche, relative, or other childcare arrangement.

The issue of childcare also came up frequently during focus group discussions. One woman lawyer, also a mother, summed up her solution: "You need supportnannies." Clearly, this was not so true of the male lawyers surveyed, $39 \%$ of whom had a partner who was not in paid employment and a further $21 \%$ had partners working only part-time outside the home. In contrast, $92 \%$ of the women surveyed had partners working full-time outside the home. Only $4 \%$ had partners engaged in unpaid work in the home and a further $4 \%$ had partners working part-time outside the home.

Thus, there is a marked disparity between men and women lawyers, in terms of their family or parental status, their childcare arrangements, and the occupation of their spouses or partners. This issue was raised in focus group discussions. One woman commercial partner in a solicitors' firm noted that "We are the first generation of women to work full-time all our lives, women in our forties. The men above us in their fifties all have wives at home." She and others also remarked that until recently a higher proportion of the small number of women partners had remained unmarried, compared to male partners.

The need for men to take an equal share of responsibility in the home, where both partners are working, was stressed by many. One woman said "As for children, a lot depends on the other person, if there is one, in the relationship, and their job...." Another said:

It's fundamental that home life be more equally carried by men, so that your social life doesn't have to stop as well. The domestic burden must be spread more evenly. Women always assume the homemaking role, it's our own fault. It's up to us to get men on board. 
449 Studies referred to earlier in this article have established 450 the difficulty of achieving work/life balance in the legal 451 profession, and the specific impact of this difficulty upon 452 women lawyers. Among Irish lawyers, the issue of how to 453 achieve balance was seen as especially problematic for 454 those women with children, many of whom were very 455 pessimistic about the prospect of achieving any kind of 456 balance. One woman solicitor summarised her predica457 ment thus:

I'm a bit negative-I think it's impossible. I think women can't have it all. It's something we bought into, talking about children. I knew it was going to be difficult, but for me it can't be done... Even being there is difficult sometimes, always the time factor, conflict. I work four days now after the birth of my child, but I haven't got it right or figured it out. The price is high.

Another woman agreed with this view, saying she had asked herself recently:

What did I do wrong? All our mothers were stay at home. We were carried by the feminist revolution, we got on this wave; house, job, children. Is it a myth, a chimera? It's very hard to balance.

\section{And another said:}

I feel I work too hard...I am hoping to change that some day soon....I try to manage work and children... It's giving giving giving, a constant juggle.

Finally, another said simply: "I think it's a myth, you can't have it all and family or partner."

Many referred to the real difficulty of trying to fit in work, family life, and some sort of social life/holiday time or leisure activity of their own. One woman said she could not achieve this sort of balance, so "Now I don't take holidays because I'm trying to manage family, juggle days and hours." Others commented that men can maintain the work/family balance, and keep hobbies or leisure activities going as well, but this is because "I don't think things have changed since my parents' time." Some thought men are better at "compartmentalising" work and family life, but others felt men had the same difficulty as women, due to the long hours and heavy workload.

The physical bond of having children was seen as another factor that was difficult to adjust to, for new fathers as well as new mothers. Also, the issue of guilt was raised, with concern expressed about the effect upon children where both parents work long hours. Due to all these factors, the desire to improve work/life balance and particularly to spend more time with children was seen as a significant reason for exiting from a legal career. However, once again, this was more frequently cited by women than men. One male solicitor noted that "many talented women come up and drop out of firms due to relationships."

However, where women leave legal careers ostensibly for family reasons, some participants in the study questioned whether this was their true motivation: had they actually enjoyed legal work itself? According to one participant: "Love of work/motivation/excitement/ adrenalin/love of argument" are the motivating factors for women working in law. These, said another, are "why and how you manage the balancing. But if you don't like the work, your family will take priority."

\section{Flexible working arrangements and leave entitle- ments}

In an attempt to address the difficulty of achieving work/life balance, legislation has been introduced providing for a range of leave entitlements, many derived from European Community employment law. ${ }^{3}$ The Maternity Protection Act 1994 entitles a pregnant employee to 18 consecutive weeks' maternity leave, around the time of birth. There is an option to take up to a further 8 consecutive weeks unpaid additional leave immediately after the 18 weeks. Although there is no obligation on the employer to pay an employee while on maternity leave, maternity benefit from the Department of Social Community and Family Affairs is usually available. ${ }^{4}$ Employer paid maternity leave is also common, but at the time of the survey, by no means widespread. However, very recently, the solicitors' professional body, the Law Society of Ireland, adopted a recommendation to ensure that maternity leave is paid by law firms to their female employees at full salary. ${ }^{5}$ Adoptive leave is available on terms similar to those for maternity leave.

The Parental Leave Act 1998 provides for an additional entitlement to unpaid parental leave, available for each parent for up to 14 weeks, to be taken before the child is five years of age. Force majeure (emergency) leave provisions in the same Act allow for short periods of paid leave for up to 3 days/year, only available when 'for urgent family reasons owing to the injury or illness' of a

\footnotetext{
${ }^{3}$ These are dependent on the status of 'employee' so are not generally applicable to barristers or partners in law firms, who are by definition self-employed.

${ }^{4}$ The rate of the statutory benefit is low. In 2005, it ranged from $€ 165.60$ to $€ 249$. Available at: 〈http://www.oasis.gov.ie/birth/ benefits_and_entitlements_relating_to_birth/maternity_benefit.html $\rangle$.

5 McCaffrey, Una, 'Solicitors vote to change maternity pay system,' Irish Times newspaper, 9 February 2005.
} 
541 family member, "the immediate presence of the employee 542 at the place where the ill or injured person is situated, is 543 indispensable. ${ }^{6}$ Other forms of leave, such as compas544 sionate leave, are discretionary. There is no provision for 545 paid paternity leave in Irish law. Nor is there any provision 546 for the taking of leave by those who are self-employed.

547 Perhaps because of this, the results of the 2002 survey 548 indicate that a large proportion of lawyers have never 549 taken any leave. The pattern of take-up of leave, where it 550 occurs, is highly gendered. Among male lawyers 551 participating in the survey, the maximum number availing 552 of any form of leave was as follows: paid sabbatical/study 553 leave (20 men), force majeure ( 9 men), and compassionate 554 leave (7 men). Women participants had availed of: fully 555 paid maternity leave (76 women), maternity leave with 556 statutory benefit only (43 women), followed by paid 557 sabbatical/study leave (31 women), and paid compassion558 ate leave ( 30 women). A total of 19 respondents had taken 559 unpaid parental leave - all but one of whom were women.

560 The study established a similarly low level of take up 561 of flexible working arrangements more generally. More 562 women than men could avail of reduced hours among 563 legal professionals, but only 44 women and 6 men availed 564 of this arrangement. Fewer than 10 men had availed of 565 flexitime/reduced or part-time hours, while 20 female 566 respondents worked flexitime and 11 more had a job567 share or part-time arrangement. The clear gender dif568 ference in take-up of flexible working arrangements was 569 confirmed by discussions in the focus groups, where the 570 male participants agreed that it would be difficult in 571 practice for a man to avail of flexible work arrangements, 572 even where these were made available: "For a guy, you 573 have to prove you're critically ill to get it."

574 When asked why they had not taken leave or sought 575 to avail of flexible working arrangements, the most 576 common reason given was that respondents, both male 577 and female, said they have never needed it. A smaller 578 group of respondents to the survey said they regretted 579 not taking leave, but had either not been allowed to take 580 leave by their employer, were unaware of its availabil581 ity; or could not take leave due to being self-employed. 582 The persistence of this culture can mean for example 583 that women simply do not take maternity leave, even 584 where they are statutorily entitled to do so as employees. 585 One woman solicitor said that she had "returned to work 5862 weeks after the birth of each child - did not feel leave 587 was necessary." In the same vein, a woman barrister noted 588 that "due to the fact that I was self-employed I worked 589 until the day my daughter was born and returned to work 5903 days later."

\footnotetext{
${ }^{6}$ Parental Leave Act 1998, Sections 13 and 14.
}

The difficulty with taking maternity leave was emphasised further in focus group discussions. One real problem is that even where family leave was negotiated for all partners and/or employees in a firm, in practice, men do not take it, so the pressure is on women to: not take it either, or to cut it short. One woman solicitor recalled being the first in her firm to take maternity leave some years previously and being told by a male partner "I don't know why we employ women; they go off and have babies."

Similar difficulties arose where lawyers had sought to avail of flexible work arrangements. For some, the main obstacle was the fact of being self-employed. One female solicitor commented: "This is a normal consequence of being self-employed." Another said: "Attempts to work both reduced hours and to work from home have proven difficult because of client requirements and requirements to meet fee targets."

Even for those lawyers in employment, flexible work arrangements were difficult to negotiate due to opposition from employers. One lawyer commented: "Endeavoured after birth of kids to take full period of maternity leave - unsuccessful. Also tried to work part-time for a short period i.e. 1 month — again unsuccessful." Another said simply: "Part-time working/working from homeno one here knows the drill and some have different understanding from others. Poor admin and personnel/ HR procedures."

Where lawyers had successfully negotiated the taking of leave or the introduction of flexible working, many explained that this had adversely affected their career development, confirming the findings of Kodz et al. (2002) and Hogarth et al. (2001), for example, that availing of family friendly working arrangements is often seen as a lack of commitment to one's career. Significantly more women had experienced an adverse impact on their careers when they had availed of forms of leave/flexible working arrangements. More female respondents believed that availing had affected them 'a lot' (20\%) or 'a little' (19\%) compared with their male colleagues ( $8 \%$ and $5 \%$ ).

Three main effects from the taking of such leave or flexible working arrangements were identified by respondents:

(a) loss of promotional opportunity- "any attempt to do less than full time work affects one's promotional prospects";

(b) loss of clients/earning potential - "Lost clients because of maternity leave"; "As a part-time working mother the areas of law in which I was given work were limited due to my partial unavailability. My earning potential was reduced"; "Pay remained stagnant during periods of maternity 
leave. No proper mechanisms in force for take-over of workload during maternity absence"; and

(c) negative perceptions of colleagues_- "perceived as willing to settle for less"; and this comment from a woman barrister: "When I decided to return to work full time about 9/10 years ago it took 4/ 5 years for solicitors and colleagues to accept that I was now taking the job more seriously."

However, some respondents regarded these effects as short-term only: "Maternity leave followed by returning to work part-time has probably affected my chances of partnership for the next few years but I don't think it will long term be a problem"; "Halted career progression but hopefully will not result in permanent damage."

For others, the effect was more fundamental, for example the woman solicitor who said: "I basically had to start all over again after returning to workforce." Another respondent, a woman barrister, similarly recalled:

As a result of taking short periods of time out and then working part-time I was left behind by my contemporaries who continued to advance. Following my return to work full time I had to work very hard to attempt to make up lost time and found this task very difficult.

In focus groups, it was acknowledged that availing of leave or flexible work arrangements did impact adversely, particularly upon women, since only women tended to avail. For example, few of women who worked parttime in solicitors' firms are likely to become partners. Another obstacle to advancement related to transactional work in corporate firms. If a solicitor does commercial transactional work, participants pointed out that the same team is needed throughout the deal. Thus, the nature of the job requires both long hours and continuity, so work cannot be delegated, and women partners on short time work find that they are often still working when they are supposed to be at home on a short-time week.

The disadvantage suffered by women seeking to avail of shorter working hours was summed up by one participant who recalled:

I was working on a transaction with another woman lawyer who was part-time and had to be out of the office every day at 3 pm, every time I spoke to her I could hear the fear in her voice about having to get out. It wasn't fair on her or the firm to allow her to go flexi-time and stay in that line of work.

The consensus across different groups was that the only way to manage reduced hours is to work a 4-day week, rather than to work shorter hours each day, since as one solicitor said, "The files are like ghosts, floating around-it's hard to leave them behind."

Most participants also agreed with the conclusion that, even for salaried solicitors in firms offering the option of flexible working hours, only the women avail of this arrangement-and this fact adversely affects women, since they are not seen as being sufficiently committed to their career. As one male participant asked, "If someone is on shorter time, you ask how committed are they? How much can they achieve in four days? This is a practical question, not gender-related."

However, a difference of view emerged among the male participants in terms of the availability of shorter working time or flexible working arrangements for men. Some argued that a man could now seek to work short-time and it would be received as well as if a woman sought it. However, while one man denied that availing of such arrangements disadvantaged women's careers, he asked: "Could we run a firm if all our partners did it? It would be difficult" and he added: "If a man did it you'd think he was a slacker."

Moreover, none of the male participants knew any man who had ever sought flexible work arrangements, although they pointed out some firms have male consultants who work shorter days than employees or partners - but they are not considered to be availing of 'flexible work arrangements.'

Other participants noted that in many cases men actually take time off too, but on an informal basis, for example to play golf. The double standard this entails was summed up by one woman solicitor, who said (without irony): "We don't have flexible arrangements for partners, it's not like taking a day off for golf; that's managing time, not flexible arrangements." When respondents asked about taking time out from their careers, 80 women and 21 men gave their reasons. These were highly gendered. Travel was the reason cited for taking time out by 3 men and 24 women. However, 21 women professionals mentioned family reasons including 9 women who had taken time out before/after having children. In contrast, only one male respondent mentioned family as a possible reason. Health was important to both women (17) and men (5). Other reasons related to time out between jobs, alternative employment, and leisure pursuits other than travel.

\section{Improving work/life balance}

Given all the problems identified in seeking to achieve work/life balance, respondents to the survey were asked to rank the importance of different measures that might improve work/life balance in their profession. Gender differences again emerged in the rankings offered. Women respondents generally found the adoption of a part-time or 
744 reduced hours option to be the most important of these 745 measures. Women also tended to rank the adoption of a 746 comprehensive maternity/parental leave policy as impor747 tant. By contrast, men found these measures less important. 748 Perhaps surprisingly, the provision of a workplace créche 749 was not ranked highly by respondents of either sex.

\section{Reduced/flexible work}

More than half of the female respondents (57\%) ranked the adoption of a part-time/reduced hours/flexible work arrangements scheme as 'very important' and a further $23 \%$ ranked it as 'important.' In contrast, only $37 \%$ of male respondents ranked such work arrangements as 'very important' and 26\% as important. These differences are highly statistically significant.

\section{Comprehensive WLB policies}

Almost half the women (46\%) ranked the introduction of comprehensive policies (e.g. on maternity/adoptive/ paternity/parental/force majeure leave) as 'very important' and a further $23 \%$ ranked their introduction as 'important.' Only $31 \%$ of male respondents considered the introduction of such policies as 'very important' and $24 \%$ as 'important.' These gender differences in responses were highly statistically significant.

\section{Locum/substitute}

The provision of a formalised locum/substitute scheme for those on leave/reduced hours received lower rankings by women and men and the differences between the rankings by men and women were not statistically significant. Under one-third of the female respondents ranked the provision of such as scheme as 'very important' compared with $25 \%$ of men. In addition, a further $24 \%$ of women and $22 \%$ of men ranked this as 'important.'

\section{Workplace crèche}

The provision of a crèche facility in the workplace was ranked as 'very important' by less than one-third of the female respondents (30\%) and just over one-quarter of male respondents (26\%). An additional $14 \%$ of the women and $11 \%$ of the men ranked a crèche facility as 'important.' There were no significant gender differences in the responses.

\section{Other measures to improve work/life balance}

When asked what other measures could improve work/ life balance, respondents gave many diverse answers; some suggested extremely lengthy and thoughtful lists of potential measures. A substantial number focused on the lack of any provision for childcare/maternity facilities among barristers, suggestions to remedy this included: "Provision of creche facilities in or near the law library part subsidised"; "Maternity paid by Bar Council"; "Some kind of recognition that women should have at least 3 months leave when recovering from the birth of a child and that work and loyalty briefing should take this into account."

One barrister emphasised the importance of measures like these, and the effect of their absence on her career and life:

There appears to be no system in place whereby 'temporary' or 'locum' barristers can be taken on in a case while the original barrister is on maternity leave. There should also be a formal system whereby cases are not set down for trial during a barrister's maternity leave. There needs to be a new culture in the legal profession including the law library whereby pregnant women are respected and given certain rights. The present position is that having a baby adversely affects your career unless you come back to work almost immediately after the birth. For me, this is the single most difficult aspect of being a barrister-I have been putting off the prospect of pregnancy for that reason.

However, the majority of answers fell into the general category of easing the pressure of work or changing the long hours culture: "Work/life balance within own control"; "The ability to take leave for a year or two to have a family and then to be able to resume career at full speed"; or the following suggestion:

Home working/annualised hours/term-time working/ public transport it has a serious impact on hours. Electronic file/laptops enabling home working. Remembering that the whole person comes to work i.e. with the fact that they may have family commitments too.

This attempt to tackle the culture of long hours was echoed by others, some of whom took a particularly pessimistic view: "The law is still a male-dominated area especially as they are normally 'partners.' Very few women in my area have been made 'partners.' V. inflexible hours. Huge pressure of work. Very hard on your own personal life. Very difficult life."

However, there were many innovative solutions offered from within the solicitors' profession: "Refresher courses targeted at persons wishing to return to work after some years absence"; "Options for leave during school holidays even unpaid"; "Job sharing. Colleagues in Law Centres can avail of this and it seems to work very well"; "Law Society to promote technology awareness to provide for more 
flexible routine e.g. parent can work more effectively from home..."

Barristers also offered some creative suggestions:

Proper insurance for time out"; "Paid devilling from a central fund of the bar..."; "A chance to get reasonable affordable desk/office facilities and an improved communal computer room..."; "Increased use of IT throughout courts system to reduce outdated work practices.

\section{Conclusion-'struggling with juggling'}

As this paper outlines, the 2003 Irish lawyers' survey demonstrates that a marked gender difference is evident in the ability to achieve work/life balance in the legal professions in Ireland. First, male lawyers are more likely to have a spouse or life partner who is working part-time or working in the home, whereas only a very low proportion of women lawyers have a spouse or life partner in any of those categories. Of those women who have a spouse or life partner, the majority of their partners are working full-time outside the home.

Second, a marked gender difference is discernible in terms of the findings about children. According to the survey, women lawyers are less likely to have children than men. Of those women who do have children, the norm is to have only one or two, whereas the tendency among male legal professionals is towards larger families. Men tend to have their children cared for by their life partner, whereas women are more likely to use a childminder or crèche.

Demand for, and take-up of, work/life balance options also varies according to gender. Men are reluctant to avail of family leave or flexible working time arrangements; so, when women do, it impacts, or is perceived to impact, adversely upon their careers since colleagues or superiors may question their commitment to their professional role. This is particularly so as 'commitment' to practice is valued above all else. Double standards thus apply, to the detriment of women within the legal professions in Ireland. As a result, many women are struggling with the impossible task of trying to balance a busy working life with the raising of children and the running of a household -and are selling themselves short in terms of social life, holidays or leisure pursuits. Creative solutions were suggested by some participants to the study as to how pressures might be eased in legal work - but many others saw the struggle as an inevitable part of a legal career.

As a result of the gender divide on work/life balance issues, both male and female lawyers participating in the study agreed that the most important way to improve opportunities for women in law is to achieve a greater facilitation of work/life balance and to change the 'long hours' culture. Clearly, other issues also contribute to the existence of structural gender discrimination. The study identified, in particular, a persistent culture of exclusion, described by many women lawyers as an 'old boys club.' This culture operates to deprive women of the chance of participating in sporting and social networks and events that are highly influential in furthering a legal career. As Sommerlad and Sanderson (1998) have written, this exclusionary culture means that women are less likely to develop the sort of 'social capital' necessary for promotion, and certainly is a significant factor in hindering women's career paths. However, the greatest obstacle to women's career progression identified by the study remains the difficulty of achieving work/life balance.

The study therefore indicates a demonstrable need for the adoption of policies on work/life balance by the professional bodies, and a need for employers to be more flexible in accommodating and facilitating homeworking, reduced hours, and other flexible working arrangements. Similarly, legal professionals need to be made aware, by professional bodies and employers, of their statutory and any additional employee rights in relation to maternity, parental leave and work/life balance arrangements. ${ }^{7}$ However, in order for real balance to be achieved for working lawyers, this sort of policy change will need to be supplemented by action to ensure that employees do not suffer disadvantage to their careers when taking family-related leave, or when availing of flexible working arrangements.

In addition, it will be necessary for professional bodies to provide a system of locums or substitute professionals who can be appointed to temporarily replace men and women who take leave. The demographic findings of the study indicate that there will be an increasing demand for childcare facilities among lawyers in the future, and this demand should be met through the introduction of créches at legal workplaces and/or financial concessions towards childcare costs.

Despite the feminisation process in the legal professions, evident over the last two decades, the idea that women will inevitably 'trickle up' through the legal hierarchy by dint of sheer volume of numbers has been exposed as a fallacy. In Canada, for example, on-going barriers to women's career progression were reviewed in a report published 10 years after a seminal study conducted in 1993 by the Canadian Bar Association Gender Equality

\footnotetext{
${ }^{7}$ The recent recommendation of the Law Society of Ireland, referred to earlier, that maternity leave be paid by law firms to their female employees at full salary is a welcome example of good practice.
} 
936 Task Force (CBA, 1993). The follow-up report noted that, 937 although women have been entering legal practice in 938 significant numbers since the end of the 1970s, they have 939 yet to make the inroads in career advancement comparable 940 to their male contemporaries (CBA, 2003). Similarly, an 941 international research project compiling data on women 942 lawyers across 15 countries and four continents also iden943 tified particular issues impeding women's career progres944 sion as lawyers, despite the increasing numbers of women 945 entering legal practice (Schultz \& Shaw, 2003).

946 The legal professions in Ireland, and elsewhere, have 947 become dramatically feminised over the last few decades, 948 as evidenced by the recent increase in women entering 949 legal studies. But this study, like those conducted in other 950 jurisdictions discussed earlier, confirms that significant 951 difficulties are encountered by women when confronted 952 with the need to combine work and family responsibil953 ities. In particular, a consensus emerges from the literature 954 that parenthood does not adversely impact on the careers 955 of men to the same extent. Changes in the structuring of 956 legal work and family work are clearly required to address 957 this gender imbalance. Cultural changes are what will 958 ultimately provide the necessary means to end the 959 ongoing 'struggle to juggle' for women lawyers, both in 960 the public and in the private sphere.

Canadian Bar Association (2003). Annual equality report, ten years into the future: Where are we now after touchstones? Ottawa: CBA.
Collier, Robert (1998). Masculinities, crime and criminology. London: Sage.

Connell, Robert (1995). Masculinities. Cambridge: Policy.

Drew, Eileen (2005). Work/life balance: Senior management champions or laggards? Women in Management Review, 20(4), 262-278.

Drew, Eileen, Murphy, Candy, \& Humphreys, Peter (2003). Off the treadmill: Achieving work/life balance. Dublin: Family Friendly Framework Committee.

Eisenstein, Zillah (1981). The radical future of liberal feminism. London: Longman.

Hakim, C. (2000). Work-lifestyle choices in the 21st century: Preference theory. Oxford: Oxford University Press.

Hogarth, Terence, Hasluck, Cris, Pierre, Gaëlle, et al. (2001). Worklife balance: 2000, baseline study of work-life balance practices in Great Britain. London: Department of Education and Employment.

Jack, Rand, \& Crowley Jack, Dana (1989). Moral vision and professional decisions: The changing values of women and men lawyers. New York: Cambridge University Press.

Kodz, Jenny, Harper, Heather, \& Dench, Sally (2002). Work-life balance: Beyond the rhetoric, research report no. 384. Brighton: Institute for Employment Studies.

Mata Greenwood, A. (2001). Gender issues in labour statistics. In M. F. Loutfi (Ed.), Women, gender and work: What is equality and how do we get there? Geneva: International Labour Office.

O'Donovan, Katherine (1985). Sexual divisions in law. London: Weidenfeld.

Olsen, Frances (1983). The family and the market: A study of ideology and legal reform. Harvard Law Review, 1497.

Pateman, Carol (1988). The sexual contract. Cambridge: Polity Press. Schultz, Ulike, \& Shaw, Gisela (Eds.). (2003). Women in the world's legal professions Oxford: Hart Publishing.

Sommerlad, Hillary, \& Sanderson, Peter (1998). Gender, choice and commitment: Women solicitors in England and Wales and the struggle for equal status. Aldershot: Ashgate.

Thornton, Margaret (1996). Dissonance and distrust: Women in the legal profession. Melbourne: Oxford University Press.

Walby, S. (1990). Theorising patriarchy. Oxford: Basil Blackwell.

Ivana Bacik is Reid Professor of Criminal Law, Criminology, and Penology at Trinity College Dublin and a practising barrister. She has written on criminal law, criminology, human rights, and equality issues, is author of Kicking and Screaming: Dragging Ireland into the 21st Century (O'Brien Press, 2004), and co-author (with Cathryn Costello and Eileen Drew) of Gender InJustice: Feminising the Legal Professions? (Trinity College Dublin Law School, 2003).

Eileen Drew is a Senior Lecturer in the Statistics Department and Centre for Gender and Women's Studies Trinity College. Her recent publications include: Off the Treadmill: Achieving Work Life Balance (Family friendly Framework Committee), Gender Equality in the Civil Service (IPA, 1999), and Women, Work and Family in Europe (Routledge, 1998). Her research has involved analysis of demographic and labour market statistics at national and EU levels and company based Equality Audits/Reviews. She co-authored Gender InJustice: Feminising the Legal Professions? (Trinity College Dublin Law School, 2003) with Ivana Bacik and Cathryn Costello.
987 